\title{
Da avalanche lírica em redes sociais: remediações poéticas em snow, de shelley Jackson
}

Vinícius Carvalho Pereira ${ }^{1}$

Introdução

O IMPACTO DAS REDES SOCIAIS DIGITAIS NA PRODUÇÃO, CIRCULAÇÃO E RECEPÇÃO DE LITERATURA - E, MAIS especificamente, de poesia - vem crescendo rapidamente nos últimos dez anos e causando significativas transformações no campo literário internacional. No bojo dessas mudanças, considerando apenas uma das plataformas que mais crescem hoje, o Instagram², podemos notar a presença de poetas já consagrados por suas publicações no meio impresso e que agora optam por também divulgar seus trabalhos na rede (como, no Brasil, Fabrício Carpi Nejar - @fabriciocarpinejar ${ }^{3}$, com 667 mil seguidores); novos artistas que se lançam na cena literária com textos produzidos especificamente para as redes sociais (como a jovem indocanadense Rupi Kaur - @rupikaur_, com 3,9 milhões de seguidores); e grandes casas editoriais que têm investido a maior parte de seus esforços e recursos publicitários para divulgação por meio de perfis próprios em plataformas online (como a Companhia das Letras - @companhiadasletras) ou por intermédio de booktubers, ou influenciadores digitais do mercado literário (tais qual Tatiana Feltrin - @tatianafeltrin, com 96,1 mil seguidores).

Diferentes pesquisas acadêmicas e jornalísticas ${ }^{4,5}{ }^{6}$ têm evidenciado como os números acima indicam tendências na cultura popular da Internet que se traduzem também em impactos financeiros no mercado editorial. Nesse sentido, têm se tornado frequentes afirmações de que a dinâmica das redes sociais permitiu um novo fôlego ao mercado de livros impressos de poesia, gênero que há muito vinha enfrentando redução progressiva nas vendas. No Brasil, por exemplo, segundo dados obtidos pela empresa de pesquisa de mercado GFK, divulgados pela Veja ${ }^{7}$ na matéria "Instapoetas, o fenômeno que tirou a poeira da poesia”, dos dez títulos de poesia mais vendidos no país entre janeiro e agosto de 2018 , cinco eram de autoria de instapoetas.

Tal neologismo designa uma nova geração de escritores, em sua maioria jovens, que criam textos breves para circulação e consumo no Instagram, frequentemente junto a desenhos ou fotografias produzidos com smartphones. Conforme o que aqui

\footnotetext{
${ }^{1}$ Professor do Departamento de Letras e do Programa de Pós-Graduação em Estudos de Linguagem da Universidade Federal de Mato Grosso (PPGEL/UFMT). Doutor em Ciência da Literatura pela Universidade Federal do Rio de Janeiro (UFRJ). Contato: viniciuscarpe@gmail.com.

${ }^{2}$ Criada em 2010 para compartilhamento de fotos (e hoje também vídeos curtos), a rede social Instagram conta com mais de um bilhão de usuários ativos por mês e pertence à corporação Facebook. Tal número, como todos os demais quantitativos indicados neste artigo com referência a usuários, seguidores, postagens etc., foi colhido no final de março de 2020, quando da redação deste texto.

${ }^{3}$ Para fins de indicação dos perfis no Instagram indicados neste artigo, reproduz-se a convenção adotada na plataforma, em que os nomes de usuários são precedidos pelo símbolo @.

${ }^{4}$ MILlner, Maggie. Instapoets Prove Powerful in Print. Poets \& Writers Magazine, California, v. 46, n. 4, 2018.

${ }^{5}$ RodrígueZ-GaONA, Martín. La lira de las masas: Internet y la crisis de la ciudad letrada. Uma aproximación a la poesía de los nativos digitales. Madrid: Páginas de Espuma, 2019.

${ }^{6} \mathrm{How}$ Instagram Saved Poetry. The Atlantic. 2018 . Disponível em: <https://www.theatlantic.com/technology/archive/2018/10/rupi-kaur-instagram-poet-entrepreneur/572746/>. Acesso em: 29/03/2020.

${ }^{7}$ INSTAPOETAS, o fenômeno que tirou a poeira da poesia. Veja. 2018. Disponível em: <https://veja.abril.com.br/especiais/instapoetas-o-fenomeno-que-tirou-a-poeira-da-poesia/>. Acesso em: 02/04/2020.
} 
estamos chamando de paratextos ${ }^{8}$ empregados por esses mesmos jovens (tais quais as autodenominações como "poeta", "instapoeta" etc. nos seus perfis na rede, ou as hashtags \#poesia e \#instapoesia, que funcionam como metadados de indexação e categorização de suas postagens), seus curtos textos devem ser lidos como espécimes do gênero lírico. Essas indicações, indissociáveis dos projetos midiáticos conduzidos por tais usuários (e pelas corporações a que se filiam), ajudam a construir o horizonte de expectativa ${ }^{9}$ de seus leitores, os quais são instados a ler essas postagens como instantâneos poéticos a serem consumidos nas telas de smartphones, curtidos e compartilhados com outros usuários, nas dinâmicas de construção de capital social caras às redes digitais.

Ao analisar o fenômeno cultural da instapoesia no mundo das letras na Espanha, Martín Rodríguez-Gaona ${ }^{10}$ chega a algumas conclusões que quiçá possam ser estendidas a outros contextos. O título de sua obra, La lira de las masas, já sugere a lente analítica que o pesquisador propõe para a leitura das manifestações poéticas por ele tratadas como "poesia pop tardoadolescente". Como características principais desses artefatos culturais, em decorrência do atravessamento pelo capitalismo pós-industrial e sua dinâmica publicitária, Rodríguez-Gaona destaca o “anti-intelectualismo, [...] a emotividade" ${ }^{\prime 1}$, os "privilégios midiáticos e comerciais"12 e sua posição fronteiriça "entre o popular e o populismo"13. Por outro lado, a fim de evitar perigosas generalizações, o pesquisador usa modalizadores em determinadas passagens de sua obra, ao dizer, por exemplo, que "a poesia de grande parte dos nativos digitais, em comparação com a de seus imediatos mais velhos, é eminentemente menos literária e intelectual, mais cotidiana, pessoal e, inclusive, antiartística [...].”14,15

Do mesmo modo, reconhecemos aqui essas características marcantes na dinâmica literária no Instagram, em que milhões de textos breves supostamente poéticos retomam imagens caras ao senso comum a fim de despertar a identificação imediata por numerosos leitores e, consequentemente, fomentar o consumo de produtos vários, desde livros impressos a vestimentas de marcas divulgadas por instapoetas. No entanto, se essa é a tônica da cena dita poética na rede, podem-se também identificar projetos desviantes, os quais se voltam para processos experimentais de criação com a mídia digital e questionam, com recursos artísticos sofisticados, suas dinâmicas de produção e consumo de informações.

Assim, na contramão da avalanche de postagens de instapoetas com vistas a uma leitura rápida e massiva, podemos encontrar iniciativas como a de Snow (@snowshelleyjackson), poema em prosa lentamente composto por Shelley Jackson ${ }^{16}$ por meio de postagens no Instagram, em que figuram fotos com inscrições na neve. Como o presente trabalho visa demonstrar, a artista norte-americana constrói uma timeline $e^{17}$ altamente lírica com imagens fotográficas e verbais do gelo (aqui em clara tensão dialética com a avalanche informacional supracitada), de maneira a instituir uma poética que paradoxalmente usa o Instagram para, em larga medida, contrariar suas dinâmicas mais comuns e superficiais de interação. Entre outras questões colocadas por essa obra, interessa ao presente estudo discutir os processos criativos de remediação que a constituem no

${ }^{8}$ GENETte, Gérard. Paratextos editoriais. Trad. Álvaro Faleiros. São Paulo: Ateliê Editorial, 2009.

${ }^{9}$ JaUSS, Hans Robert. A história da literatura como provocação à teoria literária. Trad. Sérgio Tellaroli. São Paulo: Ática, 1994.

${ }^{10}$ RodrígueZ-GaONA, op. cit.

${ }^{11}$ Ibidem, p. 40, tradução nossa.

${ }^{12}$ Ibidem, p. 151, tradução nossa.

${ }^{13}$ Ibidem, p. 167, tradução nossa.

${ }^{14}$ Ibidem, p. 162-167, grifos nossos, tradução nossa.

15 Texto original: "la poesía de gran parte de los nativos digitales, en comparación con la de sus inmediatos mayores, es eminentemente menos literaria e intelectual, más cotidiana, personal e incluso antiartística [...]”.

16 JACKSON, Shelley. Instagram: @snowshelleyjackson. 2014. Disponível em: <https://www.instagram.com/snowshelleyjackson/>. Acesso em: 29/03/2020.

${ }^{17}$ Como no jargão comum às redes sociais, entende-se aqui timeline como a sequência de postagens de um usuário vistas por ele mesmo, ao passo que o feed é o conjunto de postagens dos contatos desse usuário. 
percurso da palavra à neve, à foto, à rede, bem como os impactos que essa materialidade estratificada traz a Snow em termos de sua complexa temporalidade.

\section{Experimentando com a neve e a rede}

Shelley Jackson, a artista responsável pela concepção e execução de Snow, tem sua carreira pontuada por uma série de outros projetos experimentais envolvendo literatura e outras mídias. Entre suas criações mais célebres, estão Patchwork Girl ${ }^{18}$, ficção hipertextual digital produzida com o sistema Storyspace, comercializada à época de sua publicação na forma de CDROMs, narrando uma releitura feminista de Frankenstein; e o projeto Skin $^{19}$, iniciado em 2003 e ainda em curso, o qual consiste em uma narrativa de 2095 palavras tatuadas na pele de voluntários.

Aliando características de ambos os projetos pregressos, como o uso da mídia digital e a composição de textos por inscrições em superfícies descontínuas - para além da ubíqua fragmentação, que parece ser um traço estilístico em toda a carreira de Jackson -, a artista deu início, em 22 de janeiro de 2014, a Snow. Na conta do Instagram @snowshelleyjackson (Figura 1), vêm sendo postadas por ela há mais de seis anos fotos da paisagem do Brooklin em dias de inverno, havendo em cada imagem uma superficie coberta de neve com uma palavra inscrita no gelo.

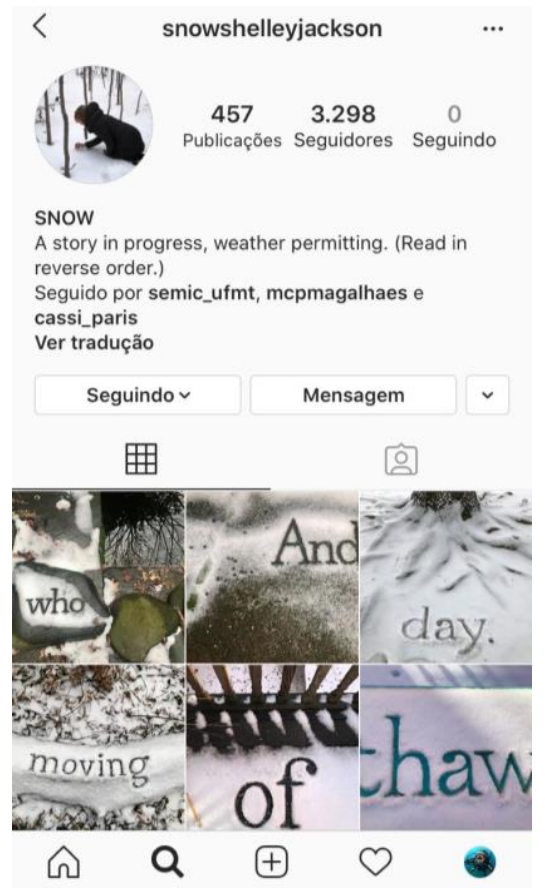

Fig. 1: Perfil de @snowshelleyjackson no Instagram. Fonte: JACKSON, 2014.

\footnotetext{
${ }^{18}$ JACKSON, Shelley. Patchwork Girl. Pendrive. Watertown: Eastgate Systems, 1995.

${ }^{19}$ Idem. Shelley Jackson's Ineradicable Stain. n.d. Disponível em: < http://www.ineradicablestain.com/skindex.html>. Acesso em: 29/03/2020.
} 
Até o presente momento ${ }^{20}$, o perfil em questão apresenta 457 publicações - isto é, 457 fotos no padrão supracitado -, as quais podem ser apreciadas isoladamente, como unidades artísticas em si, na forma de imagens disjuntas captadas pela câmera da artista e reunidas em um perfil; ou como um conjunto poético complexo, constituído pela textualidade advinda da leitura encadeada das fotografias. Nesse segundo caso, o efeito da obra é amplificado pela articulação linguística entre as palavras que cada imagem revela, ensejando um texto em prosa lírica a ser lido na timeline do perfil, de baixo para acima e da direita para a esquerda (isto é, da postagem mais antiga para a mais recente, segundo a distribuição espacial na interface do Instagram), conforme sugere a descrição na bio: "Uma história em andamento, o tempo permitindo. (Leia na ordem reversa.)”. ${ }^{21,22}$

A dialética estruturante do projeto, que oscila entre essas duas formas de leitura - e, por conseguinte, entre a imagem e a palavra, entre a fotografia e o texto, entre a justaposição e a articulação das unidades -, torna-o material e semioticamente complexo e pouco dado à leitura rápida e fragmentária que as redes sociais geralmente impõem. Nesse sentido, Snow já se afasta do modus operandi do Instagram e da prática de leitura mais comum em smartphones, que Rodríguez-Gaona ${ }^{23}$ define como uma "leitura elíptica, fragmentária ou múltipla, em breves lapsos de atenção, que inclusive pode se dar simultaneamente à audição musical, à visualização de videoclipes ou à conversação por chat" ${ }^{\text {24 }}$. Curioso é que, para subverter tal dinâmica, Jackson se valha justamente do recurso que popularizou a plataforma: a presença massiva do signo fotográfico.

Ironicamente, talvez seja esse o motivo de o perfil em questão dispor de poucos seguidores: 3298, número bastante baixo se comparado à quantidade de seguidores de perfis de instapoetas, conforme cifras mencionadas na introdução deste artigo. Analogamente, também é desconcertante, segundo a lógica das redes sociais, que o perfil em que se desenvolve o projeto Snow não siga ninguém. É como se, na não formação de vínculos dessa natureza com outros perfis, Shelley Jackson fizesse uma afirmação sobre os valores que norteiam seu projeto criativo, de paradoxal antissocialidade na rede social (ou, ao menos, nos termos do que se concebe vulgarmente como o socializar no Instagram), corroborada pela foto da artista voltada para a mídia onde constrói a escrita (a neve), e não para outros usuários.

Sob a mesma perspectiva, cumpre salientar que algumas das formas mais comuns de interação que a rede social permite acerca de conteúdos postados por terceiros, como comentários e compartilhamentos, parecem não se ajustar bem à proposta de Jackson. Uma rápida análise das fotos revela que os comentários dos seguidores do perfil são esparsos: na primeira postagem constam 27 comentários; na segunda, 5; daí em diante, a maioria das outras fotos contam com 1 ou 2 comentários cada. Kathi Inman Berens ${ }^{25}$, ao comparar os perfis @rupikaur_e @snowshelleyjackson, ressalta que este jamais responde aos comentários de terceiros em suas postagens e que, dos 24 comentários (na época de publicação de seu artigo) à primeira foto, 5 incluíam instruções a outros usuários sobre como ler o longo poema em prosa formado pelas fotos em Snow. Tal fato reforça a ideia de que o projeto de Jackson vai na contramão das tendências da instapoesia, necessitando, inclusive, de esclarecimentos explícitos sobre como os leitores devem proceder para reconhecê-lo como texto antes mesmo de interpretá-lo - demanda hermenêutica que Otávio Guimarães Tavares ${ }^{26}$ associa ao poema procedural (e a boa parte da poesia eletrônica, por extensão).

\footnotetext{
20 Todos os dados quantitativos apresentados neste artigo referem-se ao estado do perfil @snowshelleyjackson em 20 de março de 2020. Dada a celeridade do funcionamento das redes sociais, os números muito provavelmente não serão os mesmos quando da publicação deste texto.

${ }^{21}$ JACKSON, op. cit., tradução nossa.

${ }^{22}$ Texto original: “A story in progress, weather permitting. (Read in reverse order.)”

${ }^{23}$ RodRíGUEZ-GAONA, op. cit., p. 864, tradução nossa.

${ }^{24}$ Texto original: "lectura elíptica, fragmentaria o múltiple, en breves lapsos de atención, que incluso puede darse en simultáneo con la audición musical, la visualización de clips de vídeo o la conversación por chat”.

25 Berens, Kathi Inman. E-Lit's \#1 Hit: Is Instagram Poetry E-literature? Electronic Book Review. Disponível em: $<$ https://electronicbookreview.com/essay/e-lits-1-hit-is-instagram-poetry-e-literature/>. Acesso em: 30/03/2020.

${ }^{26}$ TAVARES, Otávio Guimarães. A interatividade na poesia digital. 2010. 120 fl. Dissertação (Mestrado em Literatura). Programa de Pós-Graduação em Literatura, Universidade Federal de Santa Catarina, Florianópolis, 2010.
} 
A dinâmica de compartilhamento também não parece funcionar no caso de Snow. Como parte de seus efeitos estéticos advém da leitura encadeada das imagens e das palavras nelas inscritas para formar frases, o compartilhamento de uma fotografia, em detrimento das demais, leva a uma perda do contexto que constitui a textualidade de toda a timeline como um conjunto poético em processo contínuo de atualização. De tal sorte, não é possível que outros usuários compreendam, apenas a partir de uma imagem desgarrada em seu feed, a tessitura que constitui o projeto, sobretudo em termos do estrato verbal. Fenômeno similar, aliás, dá-se também quando um seguidor do perfil recebe em seu feed uma nova postagem de @snowshelleyjackson, exibida em meio às atualizações de status de seus demais contatos na rede, e não na sequência das fotos de Snow.

Outro fator caro à dinâmica das redes sociais subvertido por Shelley Jackson é da ordem da temporalidade. À aceleração e à instantaneidade que marcam a circulação de informações em ambientes como o Instagram, este projeto artístico contrapõe uma dinâmica outra, marcada por mais de seis anos de existência do perfil na rede, tempo de vida significativamente longo para um espaço de carreiras muitas vezes meteóricas.

Além disso, se muitos instapoetas pautam sua atuação na web por máximas do marketing digital, como a de que a constância de publicações "fideliza" os seguidores, Snow se desenvolve segundo outra performance ao longo do tempo. Uma análise da periodicidade ${ }^{27}$ das postagens permite notar que, logo no início, muitas postagens eram feitas no mesmo dia (por exemplo, 24 em 29/01/2014; 64 em 04/02/2014; 110 em 13/02/2014), mas que os quantitativos diários logo caem (com 3 postagens em 14/02/2014; 2 em 15/02/2014; 2 em 16/02/2014 etc.), ainda que com alguns picos no início de anos posteriores. Assim, em vez de uma periodicidade constante, o que se vê é um ritmo muito intenso no começo do projeto (e no início de cada novo inverno), mas uma redução na frequência de postagem nas datas seguintes, talvez pela necessidade de garantir um processo sustentável a longo prazo, dado que Snow foi concebido para durar alguns anos. Há que se ressaltar, porém, que a periodicidade de que se trata neste momento é a da publicação das imagens (quando as fotos são postadas), e não necessariamente a de sua captação (quando as fotos são "tiradas"). Seria improvável haver uma relação de 1:1 entre ambas as temporalidades, especialmente se pensarmos nos esforços necessários para composição de cada imagem e na quantidade de fotos postadas nos primeiros dias de 2014.

$\mathrm{Na}$ verdade, a periodicidade das postagens é permeada pelo intrincado compósito das quatro mídias que se estratificam no projeto: o texto verbal do poema em prosa, a neve em que são inscritas as palavras, as fotografias da paisagem com intervenção da artista e a rede social em que estas são postadas. Se o descompasso entre os tempos da criação, do enunciado e da enunciação é objeto comum à análise literária a partir das contribuições do Estruturalismo, o quadro se complexifica ao tratarmos da textualidade de Snow. Afinal, esses três tempos convergem na composição do texto verbal da obra (possivelmente elaborado antes das demais etapas do projeto), mas sua inscrição na neve depende ainda de outras duas variáveis: as condições climáticas no Brooklin (onde Jackson desenvolve seu trabalho e onde só neva em alguns dias de inverno) e a capacidade da artista de riscar o gelo conforme um padrão caligráfico que se repete ao longo dos anos (Figura 2).

\footnotetext{
${ }^{27}$ Esta análise foi empreendida com base em dados coletados por um script gentilmente desenvolvido, a pedido do autor deste artigo, pelo professor pesquisador Jivago Medeiros Ribeiro, da Universidade Federal de Mato Grosso (UFMT). O script, que pode ser encontrado em < report?fbclid=IwAR3ipbe6AuHTIo86o5BxF2tMs2uP8qEOYefJBL4YxI2gZGRY147O_19ua5A >, permite acessar o perfil na rede Instagram e levantar dados como o número de postagens por data de publicação e o respectivo quantitativo de "curtidas", bem como a URL de cada postagem, gerando uma planilha com tais informações. Trata-se, pois, de profícuo material para exercício de distant reading da materialidade discursiva de @snowshelleyjackson.
} 

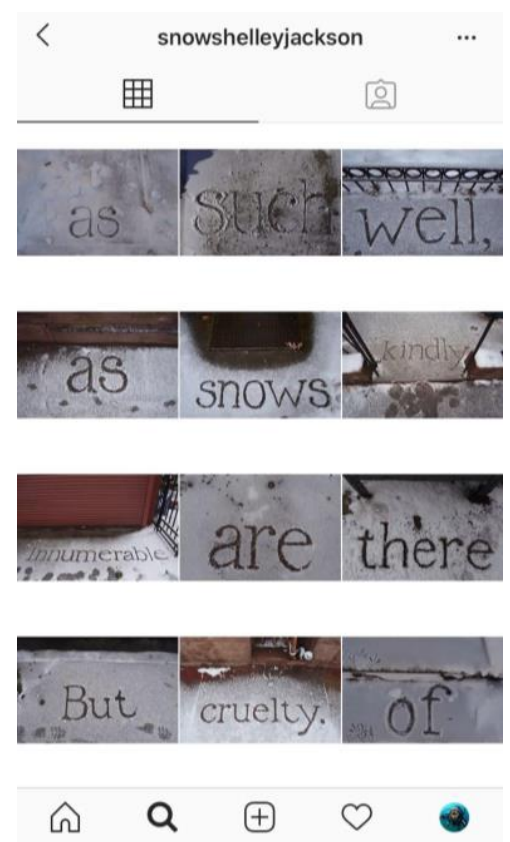

Fig. 2: Imagens postadas por @snowshelleyjackson no Instagram.

Fonte: JACKSON, 2014.

A contingência climática que a proposta impõe acaba por estabelecer, por meio de uma vinculação temporal, uma relação inextricável entre o real (o regime de estações no hemisfério norte, o aquecimento global e a precipitação de flocos de gelo) e o virtual, negando pressupostos teórico-críticos de um hiper-real que, pela tecnologia, negasse o mundo material. Este, a seu turno, se insinua também em outras camadas midiáticas de Snow, como, por exemplo, a fotográfica, na medida em que sombras e luzes são projetadas pelos objetos fotografados ou mesmo pelo corpo da fotógrafa quando da captação das imagens. Assim, mesmo a momentaneidade comumente associada às imagens obtidas com smartphones e publicadas em redes sociais não pode ser desvinculada de um ponto zero da enunciação - o ego hic nunc do registro do instantâneo, que define a perspectiva da fotógrafa no ato da captação e postula, por conseguinte, o ponto de vista do espectador, num tempo diferido.

Ainda em termos da temporalidade inerente à neve como meio - condição que aqui o gelo assume no contato com as demais mídias ${ }^{28}$-, é interessante pensar como o ritmo de inscrição por Jackson é determinado pela temperatura do material e sua resistência à pressão dos dedos, desencorajando uma produção acelerada. Afinal, se é rápida na fotografia digital a ação do "lápis da natureza" 29 , na forma da luz captada pela objetiva e instantaneamente processada em algarismos binários, é lenta em Snow a ação do "lápis da artista" - no caso, seus dedos (em claro trocadilho com o que seja o digital).

É lento. A cada inverno eu só consigo fazer, digamos, um parágrafo. Cada palavra leva um longo tempo - cada letra leva um longo tempo. Meus dedos e dedões ficam dormentes. (Num inverno eu peguei pneumonia!) O lento trabalho manual é parte do interesse, para mim; é interessante em si mesmo como algum tipo de combinação bagunçada de caligrafia e engenharia, mas também pela perversidade de fazer um trabalho tão doloroso em algo que vai desaparecer quase que tão logo eu termine. ${ }^{30} 31$

\footnotetext{
${ }^{28}$ Ibidem.

${ }^{29}$ Talbot, William Henry Fox. The Pencil of Nature. New York: Da Capo Press, 1969.

${ }^{30}$ JACKSON, Shelley. Room for So Much World: A Conversation with Shelley Jackson. [Entrevista concedida a] Scott Rettberg. Electronic Book Review, January 6, 2019. Disponível em: <https://electronicbookreview.com/essay/room-forso-much-world-a-conversation-with-shelley-jackson/>. Acesso em: 30/03/2020. Tradução nossa.

${ }^{31}$ Texto original: "It is slow. Every winter I can only do, say, a paragraph. Each word takes a long time - each letter takes a long time. My fingers and toes go numb. (One winter I caught pneumonia!) The slow handiwork is part of the interest, for
} 
Limitada pela disponibilidade de neve e por suas capacidades de riscar o gelo com precisão enquanto suporta o desconforto térmico, Jackson tem de proceder lentamente, o que justifica a duração do projeto e sua cadência de execução estranha ao ritmo acelerado do Instagram. Some-se a isso ainda o paradoxo incontornável entre a efemeridade da neve como mídia - dada a iminência do degelo - e a suposta permanência das imagens postadas na rede social, conquanto estas também estejam sujeitas a outra forma de desaparecimento, pela remoção ou deleção de dados.

A tensão entre permanência e evanescência também pode ser observada em uma leitura mais de perto de muitas das imagens constitutivas de Snow, como a que consta na Figura 3.

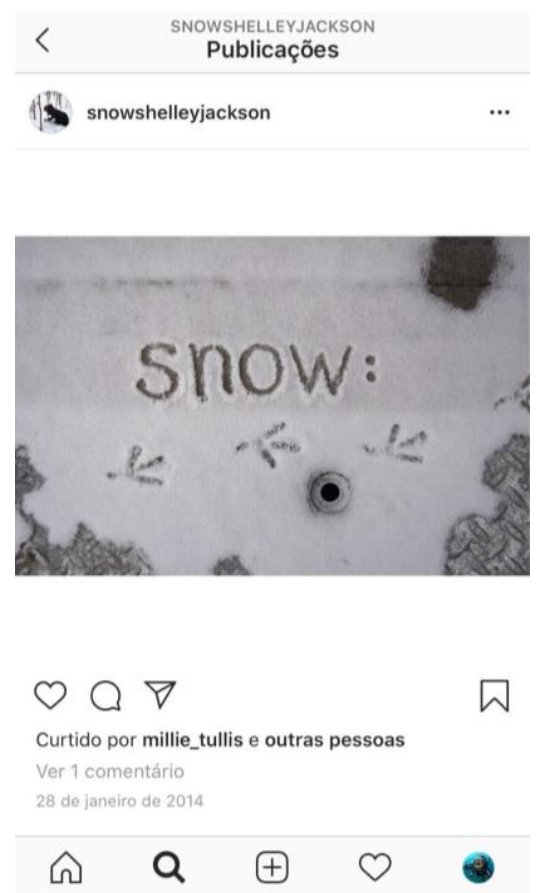

Fig. 3: Imagem postada por @snowshelleyjackson no Instagram.

Fonte: JACKSON, 2014.

$\mathrm{Na}$ leitura desta imagem, se adotamos a terminologia da Semiótica de matriz peirceana ${ }^{32}$, podemos nomear com mais precisão algumas das instâncias em que os signos visuais remetem dialeticamente à temporalidade. No plano da primeiridade, isto é, aquele em que operam os ícones, figura a reprodução fotográfica de entes que se apresentavam à frente da câmera da artista, destacadamente o piso metálico antiderrapante, a neve sobre ele acumulada, o ralo pelo qual ela escoa e os signos grafados no gelo. Para além das questões temporais que Snow mobiliza como um todo, explicadas mais acima, esta imagem, como reprodução icônica, ressalta uma relação física que se estabelece entre os objetos fotografados pela ação térmica ao longo do tempo: a neve que cobre o piso deixa de fazê-lo para assumir outra forma física, enquanto líquido, o qual escorreria pelo ralo para um espaço alheio à captação da lente. Então, a possibilidade de figurar ou não como signo fotográfico é aqui imposta pela temporalidade, por intermédio da ação do calor que incide sobre os objetos fotografados.

Do mesmo modo, se considerarmos o plano da secundidade, ou seja, aquele em que operam os índices, identificamos na foto duas marcas indexicais da passagem de seres vivos, os quais estão ausentes da imagem muito embora sejam aludidos pelos

me; it's interesting in its own right as some kind of messed-up combination of calligraphy and engineering, but also for the perversity of doing such painstaking work on something that will be gone almost as soon as I finish it".

${ }^{32}$ Santaella, Lúcia. A teoria geral dos signos. São Paulo: Editora Pioneira, 2000. 
traços deixados na neve: as pegadas da ave e as inscrições feitas pela artista. Em ambos os casos, não obstante se trate de rastros de ordem distinta, mantêm semelhante relação de causa-consequência (e, portanto, de anterioridade-posterioridade) entre um corpo e as marcas que ele deixa por onde passa. Tal qual no plano da primeiridade, há uma articulação temporal entre o que aparece ou não na imagem, mas agora sob a batuta da indexicalidade. E, considerando a dinâmica de intervenção da artista sobre a paisagem com vistas à fotografia, pode-se imaginar outro nível em que a temporalidade atravessa a constituição desses rastros, dado que muito provavelmente as pegadas da ave já lá estavam quando Jackson escolheu, a posteriori, a superfície nevada para aposição de sua caligrafia.

No plano da terceiridade, isto é, aquele em que se dão os símbolos, na terminologia de Peirce, é o poder verbal da nominação que instala as relações temporais, posto que, por convenções linguísticas, toma-se um conjunto de traços sobre a neve como o significante "snow" ("neve”), o qual tem por significado o conceito de precipitação sólida de gelo na atmosfera e por referente a mesma neve sobre a qual o signo foi escrito. Assim, para que a relação significante/significado/referente se instancie nesta imagem, há que se ter primeiro uma neve material, sobre a qual se deite o signo que a ela mesma remete.

Indo um pouco mais além, toda vez que a palavra "snow(s)" é fotografada por Jackson numa superfície nevada diferente (e há até agora vinte e cinco ocorrências desse termo entre as fotos no perfil), é como se a autora se perguntasse, em última medida, o que é a neve, ou de quantas formas distintas a mesma pode se apresentar sem perder sua essência. Nesse gesto, retoma-se um dos mais célebres problemas da hipótese linguística de Sapir-Whorf, segundo a qual a estrutura de uma língua define a percepção da experiência por seus usuários ${ }^{33}:$ de quantas formas diferentes um esquimó nomeia as diversas coisas que agrupamos sob o rótulo de "neve"? Ou, no caso do projeto de Jackson: quantas palavras diferentes há encobertas pelo signo "snow" - e quantas coisas diferentes há sob o conceito de "neve"?

Tomadas como processos, mais do que como produtos, as imagens em Snow - e o conjunto poético que elas formam na timeline do perfil - acabam por formar um longo poema em prosa multimidiático, conduzindo o espectador à reflexão sobre sua materialidade estratificada. Na superposição de todas essas mídias, observamos uma importante tendência da cultura contemporânea: a remediaçãa ${ }^{34}$, isto é, o processo pelo qual uma mídia é representada na outra através de um jogo cruzado de signos, como quando vemos uma palavra grafada na neve, a neve fotografada pela artista e, na sequência, a foto postada numa rede social. Na cultura digital, processos como esses se tornam cada vez mais frequentes, sobretudo porque todos os dados de vídeo, de áudio, de texto e de imagem hoje se convertem em zeros e uns.

Em alguns casos, como no do projeto de Shelley Jackson, as escolhas estéticas referentes à remediação se dão no sentido de uma hipermediaçãa ${ }^{35}$, ou seja, um arranjo sígnico que chama atenção intencionalmente para a multiplicidade de mídias que compõem o objeto cultural e as contingências de cada uma delas. Snow confronta diversas materialidades envolvidas no projeto, mas não abre mão da constituição de um texto poético "total” na timeline, cuja coerência é reconhecida pelo leitor que encadeie as postagens em um discurso único.

Assim, a articulação entre as partes, reforçada pelas relações sintático-semânticas estabelecidas pelos signos verbais, causa uma ilusão de unidade que pode temporariamente suspender a descontinuidade visual (entre as imagens) e material (entre as mídias), sugerindo uma ininterrupção como a da massa de neve que se espalhasse sobre uma superfície. Na próxima seção, analisamos mais detidamente o texto verbal poético de Snow enquanto esse fluxo que conecta todas as lexias da obra, a fim de compreender como o mesmo complexifica suas dobras semióticas.

\footnotetext{
${ }^{33}$ Mandelbaum, David G. (Ed.) Selected Writings of Edward Sapir in Language, Culture, and Personality. Berkeley: University of California Press, 1991.

${ }^{34}$ BOLTER, Jay David; GRUSIN, Richard. Remediation: Understanding New Media. Cambridge: MIT Press, 2000, p. 17.

${ }^{35}$ Ibidem, p. 17.
} 


\section{Catalogando a neve na rede}

Com o fito de analisar as relações estabelecidas entre o texto verbal de Snow e as demais dimensões midiáticas do projeto de Jackson, procedeu-se à leitura do discurso formado pelas 457 imagens postadas no perfil, da mais antiga para a mais recente, transcrevendo as palavras contidas nas fotos para um arquivo de software editor de texto, sobre o qual foram realizadas as operações de close reading ora descritas.

Até o momento, o conjunto de vocábulos escritos nas imagens apresenta uma arquitetura polifônica de duas vozes: a de uma personagem que, em discurso direto, descreve as possíveis descobertas decorrentes de observar bem de perto a neve; e a de um narrador que se limita a dizer "disse a menina que chorava flocos de neve" 36,37 , logo após a primeira frase da personagem. Tal sentença, ao encadear um verbo de elocução e seu sujeito, dá ares narrativos ao texto, estabelecendo um encaixamento entre as duas vozes. No entanto, não há enredo algum em Snow: o recurso ao discurso direto funciona mais como artifício para associar a longa sequência descritiva sobre as formas de neve a uma voz que se define a partir dessa mesma neve. Afinal, esta não é apenas uma menina: é “a menina que chorava flocos de neve”. Se nada mais sabemos sobre ela, é porque não se trata de personagem de facto envolvida em uma fábula. Trata-se de uma voz a divagar longa e poeticamente sobre a neve que lhe dá lugar no mundo e no texto.

Seu discurso se organiza em uma longa enumeração das formas como a neve pode ser entendida, recorrendo a metáforas inusuais para a conceptualização do gelo através de outras imagens - ora banalidades da vida cotidiana, ora acontecimentos raros -, como se nota no fragmento a seguir, transcrito e traduzido de uma sequência de 56 postagens do perfil @snowshelleyjackson:

Existem neves famintas feitas de solo e neves sacrificiais feitas das penas do peito de aves canoras, cada uma com uma continha de sangue congelado. Existem neves vermelhas e neves pretas, azuis e verdes; moradores da cidade avisam sobre neve amarela, mas poucos sabem da neve canário brilhante, de certos vales glaciais nos Alpes $[. . .]^{38,39}$

O predomínio da parataxe na concatenação das palavras parece reproduzir a sintaxe visual estabelecida entre as fotos no perfil, de modo que a justaposição de sentenças sobre os tipos de neve seja homóloga à sequenciação de imagens fotográficas do gelo com inscrições da artista. Ademais, o ritmo visual que garante coesão à timeline, oriundo das repetições do objeto fotografado e da tipografia reiteradamente adotada nas inscrições, é replicado no plano verbal pela anáfora da oração "there are snows" ("existem neves"), que pontua todo o texto não obstante as variações introduzidas por inauditos adjetivos para a neve. No exemplo acima, alguns desses qualificadores para "snow" são cores que não associamos tradicionalmente à neve, como vermelho, azul, verde etc. Tais palavras, ao mesmo tempo em que enfatizam a retórica enumerativa dos tipos de neve, destacam, por uma lógica negativa, a cor branca que o gelo adquire após a precipitação atmosférica. Note-se, aliás, que essa também é a cor prototípica da superfície mais comum de escrita a mão: o papel, remediado por Shelley Jackson como neve enquanto superfície de inscrição.

Interessante é também perceber que a assertiva "there are snows", funcionando quase como um refrão ao longo das frases,

\footnotetext{
${ }^{36}$ JACKSON, op. cit., tradução nossa.

37 Texto original: "said the girl who cried snowflakes".

${ }^{38}$ JACKSON, op. cit., tradução nossa.

${ }^{39}$ Texto original: "There are hungry snows made of ground and sacrificial snows made of the breast feathers of songbirds, each tipped with a bead of frozen blood. There are red snows and black snows, blue and green; city-dwellers warn of yellow snow, but few know of the brilliant canary snow, of certain glacial valleys in the Alps [...]”.
} 
faz um gesto ilocucionário semelhante ao das fotos que, iconicamente, indicam diferentes formas de a neve existir. Dessa perspectiva, o fato de diferentes ocorrências da palavra "snow(s)" no texto serem representadas por fotografias de inscrições distintas do mesmo termo (conforme exemplos nas Figuras 4, 5 e 6) reforça o argumento de que a multiplicidade ontológica da neve é ocultada pela unicidade lexical em nossa cultura (e eis-nos de volta ao exemplo dos esquimós e da hipótese de Sapir-Whorf).

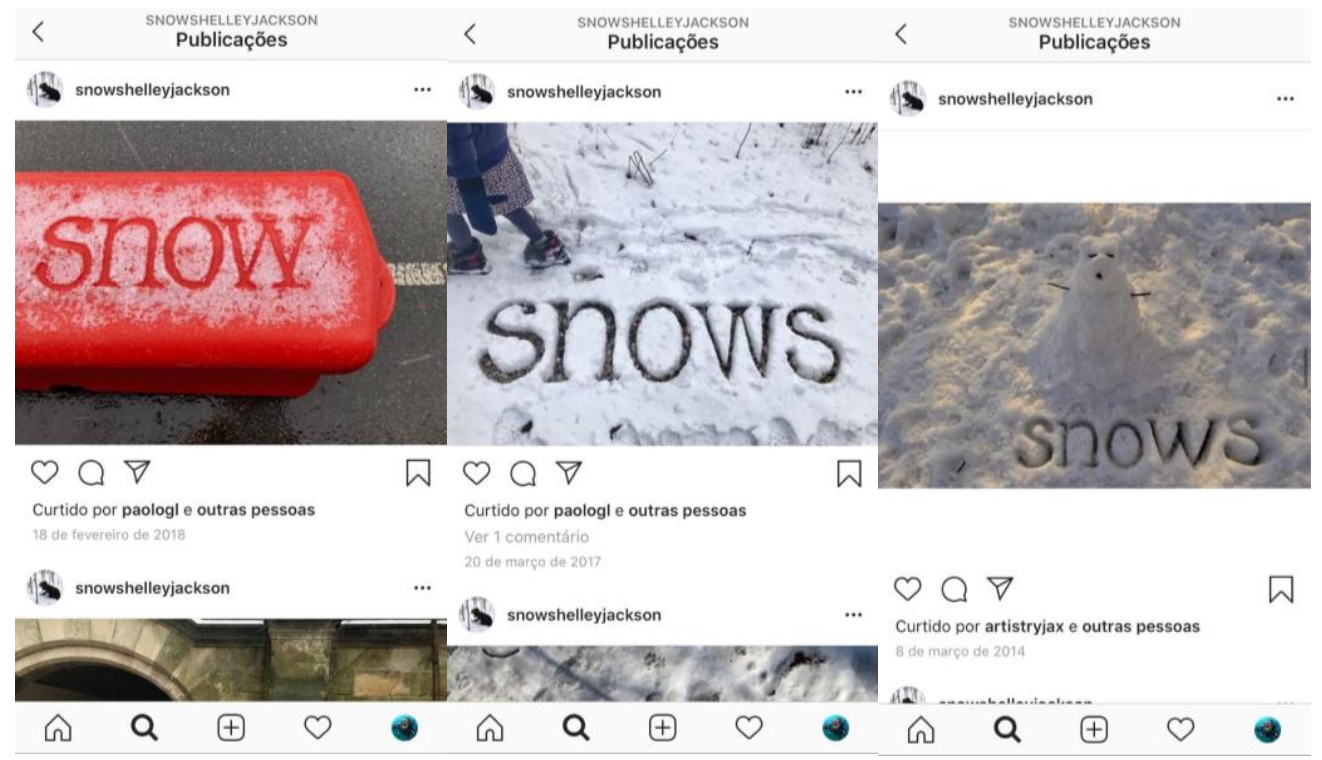

Figs. 4, 5 e 6: Imagens postadas por @snowshelleyjackson no Instagram.

Fonte: JACKSON, 2014.

Nessa empreitada de desvelar a diversidade referencial oculta sob um significante único ("snow"), Jackson, como a menina que chorava flocos de neve, convida-nos a olhar a neve mais de perto e a esquecer o modo automatizado como vemos o resultado de nevascas no dia a dia. Como a fotografia permite ver o que o olho nu não capta cotidianamente, também a poesia o faz, valendo-se de um registro linguístico que prima pela iconicidade, em detrimento da simples contiguidade metonímica ${ }^{40}$. As primeiras frases do poema em prosa já o indicam: “'Abordar a neve muito de perto é esquecer o que ela é', disse a menina que chorava flocos de neve. 'Através de um microscópio descobre-se que existem muitos tipos de neve: [...]”" ${ }^{11,42}$.

Nessa passagem, aqui transcrita e traduzida de uma sequência de 29 postagens, o olhar fresco a que nos insta o texto guarda semelhanças com a ideia de estranhamento, de Chklovski ${ }^{43}$, para quem a poesia, por meio de uma linguagem opaca, exige um adensamento e uma desnaturalização da percepção, abrindo caminho para formas renovadas de ver o mundo e os signos que o representam. Nessa perspectiva, o microscópio a que alude o texto funciona como metáfora para o ajuste de lentes exigido pela arte e a consequente reconfiguração da percepção. Sendo Snow um projeto poético captado também por objetivas (no caso, fotográficas), essa imagem óptica se torna ainda mais significativa, conotando as variadas lentes midiáticas que se sobrepõem a fim de renovar nossos sentidos diante da neve.

Tal movimento aproxima Snow de outros processos de criação experimentais que promovem uma ressignificação da

\footnotetext{
${ }^{40}$ PignatAri, Décio. Semiótica e literatura. Cotia: Ateliê Editorial, 2004, p. 24.

${ }^{41}$ JACKSON, op. cit., tradução nossa.

42 Texto original: “To approach snow too closely is to forget what it is', said the girl who cried snowflakes. 'Through a microscope one discovers that there are many kinds of snow: [...]”.

${ }^{43}$ Chklovski, Victor. A arte como procedimento. In: Todorov, Tzvetan (Org.). Teoria da literatura: textos dos formalistas russos. Trad. Roberto Leal Ferreira. São Paulo: UNESP, 2013, p. 83-108.
} 
relação entre o humano e a paisagem natural, no bojo do que se convencionou chamar de land art. Na conta do Instagram ora em análise, o chamado a repensar as formas de ver o espaço circundante e a maneira como a neve com ele interage é não só um procedimento estético, mas também ético, pois pode fomentar um despertar de consciência ecopolítica, dadas as relações diretas entre o aquecimento global e a precipitação da matéria-prima na qual Jackson faz suas inscrições ${ }^{44}$. Olhar mais de perto a neve é, portanto, olhar mais de perto o mundo em que neva, ou em que pode deixar de nevar, a depender das ações humanas nos próximos anos.

Ao convocar a atenção mais detida para diferentes tipos de neve, ou diferentes formas de que ela se investe no mundo, Snow realiza, por expedientes fotográficos e verbais (ou icônicos e simbólicos, se retomarmos a nomenclatura da Semiótica peirceana), também uma ação catalográfica a partir da remediação. Para tanto, indica categorias que emergem da observação afetiva e poética da neve, subsumidas no sintagma "many kinds of snow" ("muitos tipos de neve"). O que se segue a ele, no texto verbal, faz as vezes de um detalhado aposto enumerativo, indicando um rol de manifestações que a neve pode assumir, como “[...] neve feita de cartas não lidas de amantes não amados, e neve de metal feita de discos com extremidades serradas, para mencionar apenas um dos inumeráveis membros da grande classe das neves de guerra, pois não há fim para as formas de crueldade”45,46.

Consoante esses exemplos evidenciam, claramente não se trata de categorias exaustivas ou sistemáticas. Nos termos de Rettberg, trata-se de uma “[...] fenomenologia da neve [...]. Parece que você [Shelley Jackson] está considerando a neve como um tipo de gerador de afeto, ou talvez como um modo de enquadrar a experiência humana" ${ }^{\text {" }}{ }^{48}$. Em lugar de um discurso científico que adotasse um método indutivo de formulação de rótulos para os "tipos" de neve, o que se tem aqui é uma empreitada lírica que revela o gozo no malogro da classificação: muito embora a diversidade ontológica da neve seja inegável, nenhum sistema taxonômico pode dar conta de todas as configurações que ela assume. Justamente por ser pura substância, e não forma, a neve escapa à empresa teórica, que tem por fim sempre a postulação de uma forma que dê sentido ao mundo da matéria e da práxis.

Por mais que o par forma-matéria soe demasiado metafísico ou estruturalista, uma discussão da dimensão midiática (e, portanto, material e formal) de Snow não pode dele prescindir, como bem revela Flusser:

Se "forma" for entendida como o oposto de "matéria", então não se pode falar de design "material"; os projetos estariam sempre voltados para informar. E se a forma for o "como" da matéria e a matéria for o "o quê" da forma, então o design é um dos métodos de dar forma à matéria e de fazê-la aparecer como aparece, e não de outro modo. O design, como todas as expressões culturais, mostra que a matéria não aparece (é inaparente), a não ser que seja informada, e assim, uma vez informada, começa a se manifestar (a tornar-se fenômeno). A matéria no design, como qualquer outro aspecto cultural, é o modo como as formas aparecem. ${ }^{49}$

Considerando que um projeto de mídia, como o de Snow, é necessariamente também um projeto de design, cabe-nos

\footnotetext{
${ }^{44}$ NACHER, Anna. The Creative Process as a Dance of Agency - Shelley Jackson's Snow: Performing Literary Texts with Elements. In: MAduro, Daniela (Org.) Digital Media and Textuality: from Creation to Archival. Bielefeld: Transcript, 2017, p. 169-186.

${ }^{45}$ JACKSON, op. cit., tradução nossa.

${ }^{46}$ Texto original: “[...] snow made of unread letters of unloved lovers, and metal snow made of discs with serrated edges, to mention only one of the innumerable members of the great class of the snows of war, for there is no end to the forms of cruelty”.

${ }^{47}$ JACKSON, Shelley. Room for So Much World: A Conversation with Shelley Jackson, op. cit., tradução nossa.

${ }^{48}$ Texto original: "[...] phenomenology of snow [...]. It seems that you're considering snow as kind of generator of affect, or maybe as a way of framing human experience".

${ }^{49}$ FluSSER, Vilém. O mundo codificado. Trad. Raquel Abi-Sâmara. São Paulo: Ubu, 2017, p. 26.
} 
indagar os arranjos formais - fotográficos e verbais - pelos quais a matéria da neve se reveste de forma sensível e cognoscível na obra. Se, na seção anterior, discutimos algumas das remediações que nos fazem pensar as articulações entre o real e o virtual por intermédio de relações temporais metaforizadas pela neve, em diferentes extratos semióticos e midiáticos de Snow, o texto do poema em prosa agora nos sugere um pendor enciclopédico poético, calcado nas operações de parataxe, reiteração e definição descritas nesta seção.

O arranjo vocabular no texto verbal e a combinação visual na sequência fotográfica compõem um gesto formalizador intencional, pelo qual a artista vai listando diferentes sentidos que podem ser atribuídos à neve. Organizado como se uma enciclopédia fora, o perfil @snowshelleyjackson tece uma intrincada rede entre essas imagens (verbais e/ou visuais) da neve, as quais são apresentadas em uma ordem, mas esta é tão-somente arbitrária. Apesar de a organização sintática das palavras contidas nas fotos requerer determinada ordenação, as posições relativas entre diferentes metáforas enumeradas são contingenciais. Tanto faria dizer que há neves do tipo A e do tipo B, ou do tipo B e do tipo A. Nesse sentido, a empreitada enciclopédica se assemelha à lógica do hipertexto, conforme padrões de organização da informação para leitura multidirecional, consoante explicitado por Landow ${ }^{50}$.

Dado que a lógica hipertextual é também a que pauta o funcionamento de uma rede social como o Instagram, com navegação algo livre entre perfis, postagens e curtidas, o texto verbal produzido por Jackson acaba por fazer referência não só à neve, senão também à (hiper)mídia em que se constitui online - bem ao gosto de McLuhan ${ }^{51}$, para quem o conteúdo de uma mídia é sempre outra mídia - em clara antecipação do conceito de remediação de Bolter e Grusin ${ }^{52}$. Ao fazer esse gesto simultaneamente referencial e autorreferencial, Snow ainda nos leva a pensar sobre outras operações de remediação empreendidas com o material verbal para explorar os sentidos da neve. Na longa classificação dos tipos de neve a que se refere "a menina que chorava flocos de neve”, ganham destaque as construções ecfrásticas:

[...] existem muitos tipos de neve: aqueles feitos de diminutas pinturas de naufrágios no estilo de Bonaventura Peeters, aqueles feitos de miniaturas de fruteiras de cera, formados muito bela e realisticamente, exceto pelo tamanho; aqueles feitos de fragmentos de unhas de bebês; e aqueles feitos de escalpos de megeras aparados e tatuados, usados como dinheiro por certos povos primitivos do sul dos Urais. Existem neves feitas de faces de relógios e réguas circulares de cálculo de mapas para países não descobertos, de nuvens quebradiças de hálito daqueles que gritaram por socorro não ouvido em um dia claro de inverno. ${ }^{53,54}$

Nessa passagem, transcrita e traduzida de uma sequência de 105 postagens, observa-se que, com vistas a inventariar alguns dos tipos de neve, a voz poética recorre a uma série de relações de forma/matéria manifestas pela construção “made (up) of"

${ }^{50}$ LANDOW, George. Hypertext: The Convergence of Contemporary Critical Theory and Technology. Baltimore: Johns Hopkins University Press, 1992.

${ }^{51}$ MCLuHAN, Marshall. Understanding Media: The Extensions of Man. Cambridge: MIT Press, 1964.

52 BOLTER; GRUSIN, op. cit.

${ }^{53}$ JACKSON, op. cit, tradução nossa.

54 Texto original: "[...] there are many kinds of snow: those made up of tiny paintings of shipwrecks in the style of Bonaventura Peeters, those made up of miniature bowls of wax fruit, very beautifully and realistically formed, except for the size; those made up of the fingernail clippings of babies; and those made up of the trimmed and tattooed scalps of shrews, used as money by certain native peoples of the southern Urals. There are snows made of clock faces and circular slide rules of maps to undiscovered countries, of the shattered breath clouds of those who have cried out for help unheard on a clear winter day”. 
("feitas de"), que ressalta uma ideia de fabricação ou design, como se as distintas espécies de neve fossem feitas de coisas diferentes - ou melhor, de artes diferentes. São neves feitas de pinturas no estilo de Bonaventura Peeters, de esculturas em miniatura de fruteiras, de colagens de fragmentos de unha, de desenhos de mapas etc. Atente-se, porém, à preposição: os tipos de neve são feitos de artes distintas, e não como artes distintas. Não se trata, pois, de ut pictura poiesis, como relação de semelhança entre as linguagens, conforme a Ars Poetica de Horácio. A relação entre as diversas artes e a neve é de meio ou substância, corroborando o caráter midiático que a neve assume no processo de criação dessa obra, tão prenhe de significados como qualquer dessas outras artes seria. O foco na dinâmica de remediação é tão intenso que chega a engendrar uma dobra tautológica sem fim, quando a neve, como mídia, ressignifica a própria neve, tal qual se lê em "Existem neves que, concebendo uma neve mais perfeita, nunca caem ${ }^{55,56}$. No paradoxo da neve que, ao se pensar neve, deixa de cair (e, portanto, de fazer-se neve), o projeto de Jackson assume claramente o jogo de signos que faz vacilar limites ontológicos entre o meio, o conteúdo e a expressão; entre a palavra, a imagem e o real; entre as temporalidades do real e do virtual.

\section{considerações finais}

Ao longo deste artigo, analisou-se o projeto experimental Snow, conduzido por Shelley Jackson na rede social Instagram. Em intrincado processo criativo, a artista constrói um poema em prosa que mobiliza diferentes mídias e linguagens, em jogos de remediação e estratificação semiótica, indo na contramão das tendências cada vez mais populares no âmbito do que se convencionou chamar de instapoesia.

Em lugar de uma dinâmica constante e acelerada de produção, circulação e recepção, cara às redes sociais digitais de modo geral, Snow se caracteriza por uma temporalidade lenta e aperiódica, sujeita a contingências meteorológicas, fisiológicas, materiais e estéticas. Assim, o projeto vem se dilatando há mais de seis anos no Instagram, a despeito do número relativamente baixo de seguidores e reações nas métricas da rede (como curtir, compartilhar e comentar). Seu modus operandi parece ser justamente o de valer-se dos recursos que essa mídia oferece (como a precipuidade dos signos fotográficos) para questionar nossas formas cotidianas de olhar as imagens. Ao desacelerar a percepção e convidar ao estranhamento, Snow nos provoca uma reflexão sobre as diferentes mídias articuladas no perfil @snowshelleyjackson e sobre o modo como elas se relacionam entre si e com o mundo.

Ainda no que concerne à remediação cara ao projeto de Jackson, cumpre destacar as operações intersemióticas que Snow engendra, criando cadeias de significantes que se interpenetram de palavras, inscrições, fotografias e postagens. Nesse jogo, somos levados a pensar seu perfil no Instagram como um processo criativo enciclopédico que se propõe a investigar a multiplicidade ontológica sob o signo "snow": de quantas formas, enfim, podem a neve e seus signos existir, em meio à avalanche informacional que marca a ecologia das redes?

\section{Referências bibliográficas}

\footnotetext{
${ }^{55}$ JACKSON, op. cit., tradução nossa.

${ }^{56}$ Texto original: "There are snows that, conceiving a more perfect snow, never fall”.
} 
BERENS, Kathi Inman. E-Lit's \#1 Hit: Is Instagram Poetry E-literature? Electronic Book Review. Disponível em: <https://electronicbookreview.com/essay/e-lits-1-hit-is-instagram-poetry-e-literature/>. Acesso em: 30/03/2020.

BOLTER, Jay David; GRUSIN, Richard. Remediation: Understanding New Media. Cambridge: MIT Press, 2000.

ChKlovsKi, Victor. A arte como procedimento. In: Todorov, Tzvetan (Org.). Teoria da literatura: textos dos formalistas russos. Trad. Roberto Leal Ferreira. São Paulo: UNESP, 2013, p. 83-108.

FLUSSER, Vilém. O mundo codificado. Trad. Raquel Abi-Sâmara. São Paulo: Ubu, 2017.

Genette, Gérard. Paratextos editoriais. Trad. Álvaro Faleiros. São Paulo: Ateliê Editorial, 2009.

How Instagram Saved Poetry. The Atlantic. 2018. Disponível em: <https://www.theatlantic.com/technology/archive/2018/10/rupi-kaur-instagram-poet-entrepreneur/572746/>. Acesso em: 29/03/2020.

INSTAPOETAS, o fenômeno que tirou a poeira da poesia. Veja. 2018. Disponível em: <https://veja.abril.com.br/especiais/instapoetas-o-fenomeno-que-tirou-a-poeira-da-poesia/>. Acesso em: 02/04/2020.

JACKSON, Shelley. Instagram: @snowshelleyjackson. $2014 . \quad$ Disponível em: <https://www.instagram.com/snowshelleyjackson/>. Acesso em: 29/03/2020.

JACKSON, Shelley. Patch work Girl. Pendrive. Watertown: Eastgate Systems, 1995.

JACKSON, Shelley. Room for So Much World: A Conversation with Shelley Jackson. [Entrevista concedida a] Scott Rettberg. Electronic Book Review, January 6, 2019. Disponível em: <https:/electronicbookreview.com/essay/room-for-so-muchworld-a-conversation-with-shelley-jackson/>. Acesso em: 30/03/2020.

JACKSON, Shelley. Shelley Jackson's Ineradicable Stain. n.d. Disponível em: <http://www.ineradicablestain.com/skindex.html >. Acesso em: 29/03/2020.

JAUSS, Hans Robert. A história da literatura como provocação à teoria literária. Trad. Sérgio Tellaroli. São Paulo: Ática, 1994.

LANDOW, George. Hypertext: The Convergence of Contemporary Critical Theory and Technology. Baltimore: Johns Hopkins University Press, 1992.

Mandelbaum, David G. (Ed.). Selected Writings of Edward Sapir in Language, Culture, and Personality. Berkeley: University of California Press, 1991.

Mcluhan, Marshall. Understanding Media: The Extensions of Man. Cambridge: MIT Press, 1964.

Millner, Maggie. Instapoets Prove Powerful in Print. Poets \& Writers Magazine, California, v. 46, n. 4, 2018.

NACHER, Anna. The Creative Process as a Dance of Agency - Shelley Jackson's Snow: Performing Literary Texts with Elements. In: MAduro, Daniela (Org.) Digital Media and Textuality: from Creation to Archival. Bielefeld: Transcript, 2017, p. 169-186.

PIgNATARI, Décio. Semiótica e literatura. Cotia: Ateliê Editorial, 2004.

RODRÍGUEZ-GAONA, Martín. La lira de las masas: Internet y la crisis de la ciudad letrada. Uma aproximación a la poesía de 
los nativos digitales. Madrid: Páginas de Espuma, 2019.

SANTAELlA, Lúcia. A teoria geral dos signos. São Paulo: Editora Pioneira, 2000.

Talbot, William Henry Fox. The Pencil of Nature. New York: Da Capo Press, 1969.

TAVAres, Otávio Guimarães. A interatividade na poesia digital. 2010. 120 fl. Dissertação (Mestrado em Literatura). Programa de Pós-Graduação em Literatura, Universidade Federal de Santa Catarina, Florianópolis, 2010.

Recebido em: 17/07/2021

Aceito em: 04/10/2021 